\title{
edmetic
}

Revista de Educación Mediática y TIC

\section{Nace una nueva iniciativa educomunicativa}

Comenzamos el año 2012 con el nacimiento de una nueva revista, EDMETIC. Revista de Educación Mediática y TIC.

El sentido de su nacimiento no es otro que cubrir un espacio que, a nuestro juicio, no se encuentra totalmente cubierto, nos referimos al mundo de la educomunicación.

Desde estas páginas queremos tratar de completar la magnífica labor que revistas como Comunicar, Pixel Bit, Etic@net, Aularia, etc., están realizando en torno a esta línea de trabajo.

Hablar de educación mediática significa tomar el testigo que en 2008 la Unión Europea lanzó a todos los estados miembros sobre esta materia, donde se instaba a incorporar la educación mediática en los currículos de los distintos sistemas educativos.

EDMETIC, Revista de Educación Mediática y TIC, trata de acercar la educación en, con y para los medios a todos los niveles educativos, así como a todas sus áreas. Hablamos de incorporar la educomunicación tanto a la educación formal, como no formal e/o informal de todos los individuos.

La revista está abierta a la participación de todos aquellos investigadores e investigadoras, profesionales de la educación o interesados en la educomunicación en cualquiera de sus números, tanto con revisiones teóricas como experiencias didácticas e/o investigadoras. Todas ellas nos enriquecerán y ayudarán a crecer dentro de este campo.

Este primer número se centra en un aspecto que ha estado con todos nosotros desde que en los años 40-50 rompió la tranquilidad de los hogares 
norteamericanos, nos referimos a la Televisión. La TV ha sido querida y odiada por todos nosotros y nosotras, ha formado parte de nuestros momentos de ocio, de tristeza, de alegría incluso, a veces, se ha convertido en nuestra compañía, en nuestro "ruido de fondo" es el medio por el que nos mantenemos informados de lo que sucede en el ancho y vasto mundo.

Pero, desde este número hemos tratado de acercarnos a la nueva televisión que en el siglo XXI se está desarrollando de forma conjunta con otra herramienta estelar en nuestra vida diaria, la red Internet. Esta ha supuesto una revolución en los sistemas comunicativos, el estudio realizado por De Wit, Heerwegh y Verhoeven (2011) refleja como los jóvenes belgas en el año 2009 utilizaban Internet para su vida diaria en un 99\% de los casos, y España no se queda muy atrás. El Instituto Nacional de Estadística indica que en 2011 veintitrés millones de españoles con una edad comprendida entre los 16 y los 74 sujetos había utilizado internet en los últimos 3 meses. Como podemos apreciar, estos datos son reveladores del gran incremento que este medio está teniendo.

Junto a estas dos variables hemos unido una más, la Universidad. Institución que en estos momentos se encuentra en un gran y profundo proceso de cambio y/o transformación. A través de los artículos que conforman este primer número, nos adentraremos en conocer cómo las instituciones de enseñanza superior han incorporado la televisión a sus dinámicas diarias. Igualmente, encontraremos referencia expresa a cómo la televisión se está desarrollando en diferentes universidades españolas y a través de la propia red Internet.

No quiero cerrar estas líneas sin realizar un agradecimiento a los autores y autoras que han colaborado en este primer número, a todos ellos GRACIAS.

Verónica Marín-Díaz Editora EDMETIC, Revista de Educación Mediática y TIC vmarin@uco.es

edmetic, 1 (1), 2012, E-ISSN: 2254-0059; pp. 1-3 


\section{Referencias bibliográficas}

DE WIT, KURT, HEERWEGH, DIRK y VERHOEVEN, JEF C. (2011). Changes in the basic ICT skills of freshmen between 2005 and 2009: Who's catching who's still behind? Educational Information Technology. En prensa INSTITUTO NACIONAL DE ESTADÍSTICA (2011). Encuesta sobre Equipamiento y Uso de Tecnologías de la Información y Comunicación en los hogares 2011. Disponible en http://www.ine.es/jaxi/tabla.do?path=/†25/p450/a2011 1/10/\&file=04012.px \&type $=$ pcaxis \&L=0. 